\title{
"Why Take It If You Don't Have Anything?" Breast Cancer Risk Perceptions and Prevention Choices at a Public Hospital
}

\author{
Talya Salant, MA, ${ }^{7}$ Pamela S. Ganschow, MD, ${ }^{2,3}$ Olufunmilayo I. Olopade, MD,4,5 \\ Diane S. Lauderdale, $P h D^{6}$ \\ 'Pritzker Medical School and the History of Culture, University of Chicago, Chicago, IL, USA; ${ }^{2}$ Breast \& Cervical Cancer Screening Program, \\ Cook County Hospital, Chicago, IL, USA; ${ }^{3}$ Rush Medical College, Chicago, IL, USA; ${ }^{4}$ Center for Clinical Cancer Genetics, University of \\ Chicago, IL, USA; ${ }^{5}$ Hematology/Oncology Section, University of Chicago, Chicago, IL, USA; ${ }^{6}$ Department of Health Studies, University of \\ Chicago, Chicago, IL, USA.
}

\begin{abstract}
BACKGROUND: Despite advances in breast cancer risk assessment and risk reduction technologies, little is still known about how highrisk women make sense of their risk and assess prevention options, particularly among minority and low-income women. Qualitative methods explore the complex meanings and logics of risk and prevention that quantitative approaches overlook
\end{abstract}

OBJECTIVE: This study examined how women attending a high risk breast cancer clinic at a public hospital conceptualize their breast cancer risk and think about the prevention options available to them.

METHODS: Semi-structured interviews were used to gather data from 33 high-risk women (75\% African American) between May and August 2004. Interview transcripts were analyzed for recurrent themes and patterns.

RESULTS: Despite general awareness of their objective risk status, many women in this study reported they did not feel "high risk" because they lacked signs and symptoms of cancer. Risk was described as an experienced acute problem rather than a statistical possibility. Women also frequently stated that thinking about cancer might cause it to happen and so it is better not to "dwell on it." While screening was welcomed, women were generally skeptical about primary prevention. In particular, preventive therapies were perceived to cause problems and were only acceptable as treatment options for a disease.

CONCLUSIONS: The body of ideas about risk and prevention expressed by this population differ from the medical model. These findings have implications for risk perception research as well as for the efficacy of risk communication and prevention counseling in clinical contexts.

KEY WORDS: risk perception; chemoprevention; breast cancer; underserved populations.

DOI: $10.1111 /$ j.1525-1497.2006.00461.x

J GEN INTERN MED 2006; 21:779-785.

$\mathrm{E}$ nthusiasm and opportunities for identifying women with elevated breast cancer risk and for implementing primary prevention strategies have expanded in recent years to

A poster of this research was presented at the Department of Defense 2005 Era of Hope meeting (June 8-11, 2005, Philadelphia, PA) as a grant requirement and at the Preventive Medicine 2005 conference (February 17-20, 2005, Washington, DC) as a requirement upon winning the competition for "Best Paper in Preventive Medicine by a Medical Student."

Address correspondence and requests for reprints to Dr. Lauderdale: Department of Health Studies, University of Chicago, 5841 Maryland Ave., MC 2007, Chicago, IL 60637 (e-mail: lauderdale@health.bsd. uchicago.edu). the general medicine setting, supplementing mammography screening for early detection. ${ }^{1,2}$ Primary care physicians have increasing access to an array of tools for individual breast cancer risk assessment-including computerized models such as the Gail model and genetic tests for inherited mutations in BRCA1 and BRCA2, breast cancer susceptibility genes ${ }^{3,4}$ and a growing list of risk reduction options. Evidence-based primary prevention strategies for high risk women include chemoprevention with paclitaxel or other selective estrogen receptor modulators (SERMs) and prophylactic surgeries such as bilateral oophorectomy and/or bilateral mastectomy, which entail a $50 \%$ to $90 \%$ risk reduction for new primary breast cancers. ${ }^{5-8}$ In short, these developments allow General Internists to routinely assess breast cancer risk, provide risk reduction advice, and refer patients for further risk counseling. ${ }^{9}$

Despite these advances in technology and practice, however, little is known about how women categorized as "high risk" understand the meaning of their risk and decide about available prevention options. ${ }^{10,11}$ As primary care physicians increasingly engage in risk conversations with their patients, better awareness is needed of how individuals from diverse sociodemographic backgrounds approach and manage risk information. In particular, greater depth of understanding is needed to account for observed ethnic differences in breast cancer risk self-perceptions ${ }^{12}$ and the apparent unwillingness to use SERMs such as tamoxifen for breast cancer prevention among urban minority women.

Within the breast cancer risk perception and prevention decision-making literature, existing quantitative approaches have been unable to explain incongruent findings or to describe the full range of patient experiences, suggesting the need for alternative approaches and research settings. For example, clinical studies have demonstrated persistent heterogeneity in subjective risk perceptions and prevention decisions among women at similar levels of objective breast cancer risk. ${ }^{11-17}$ While nonrational determinants have been suggested for this heterogeneity, including sociocultural context, life experience, and emotional factors, in-depth qualitative studies of the meaning of risk and prevention decision-making among high risk patients have been few. ${ }^{10,12,18-24}$ Quantitative studies that have examined psychosocial predictors and outcomes

Manuscript received May 24, 2005

Initial editorial decision August 5, 2005

Final acceptance February 20, 2006 
of risk perceptions and prevention decisions have also tended to presume a uniformly shared definition of risk. ${ }^{11,12}$ Moreover, to the extent that theoretical models are constructed based on the variation within a patient sample, most existing research in this area has focused on predominantly white, educated, and privately insured populations who actively seek "high risk" counseling. This study thus responds to calls for qualitative studies in this field, particularly among understudied minority and indigent populations. ${ }^{10,11,25-28}$

In the current study, qualitative methods were used to examine how women attending a public hospital breast cancer high risk clinic think about their risk and decide about prevention. ${ }^{29,30}$ Semi-structured interviews explored patients' understandings of the clinic's purpose, the meaning of "high risk," thoughts about personal risk and causes of cancer, and attitudes toward available prevention approaches, including SERMs and genetic testing. Ideas about the causes of breast cancer are particularly relevant here as existing prophylactic options carry with them particular assumptions about etiology (e.g., estrogen exposure) and what counts as effective preventive action (e.g., estrogen antagonism via SERMs). ${ }^{31}$ These assumptions may conflict with a patient's own understandings, influencing whether or not she identifies herself as a "candidate" for undertaking preventive action. ${ }^{32-34}$ Likewise, reluctance to accept medical definitions of risk might be an important barrier to adopting preventive behaviors.

\section{METHODS}

\section{Research Setting}

The Breast Cancer High Risk Clinic at John Stroger Hospital of Cook County, IL is part of a triangulated program of breast and cervical cancer screening, diagnostic, and preventive care. Most clinic referrals come from primary care physicians or via one of the other program arms; the most common referral reason is having a family history of breast cancer. During the study period, 2 General Internists provided clinical breast exams, risk assessment and counseling, and recommendations about prevention strategies including chemoprevention (i.e., tamoxifen) on 1 half-day per week. Physicians assessed risk using the Gail model, which computes 5-year and lifetime risk based on individual risk factors (age, age at menarche, age at first childbirth, history of breast biopsies, and first degree family history of cancer). Based on published criteria, a 5-year Gail risk of $1.67 \%$ or higher was used as the clinical risk threshold for prescribing SERMs. ${ }^{6}$ Physicians also categorized risk of carrying an inherited gene mutation in BRCA1 or BRCA2 along a spectrum of risk from low to high based on an elicited family history. Genetic counseling was typically offered when hereditary risk was moderate to high. Most clinic patients visited twice a year and were recommended annual mammograms.

\section{Data Collection and Analysis}

Following institutional IRB approval, convenience (nonrandom) sampling was used to recruit new and returning patients attending the High Risk Clinic between May and August 2004, resulting in a cross-sectional sample. Because of limited interpreter availability, only English-speakers were eligible to participate. A \$5 gift card to a local grocery store chain was offered as compensation. Participation among those approached was 80\%; reasons for refusal included language barriers, emotional distress, or lack of telephone access, time, or interest. Refusals were similar to enrollees in age, race, and risk status (data not shown). After informed consent, a graduate student researcher (T.S.) administered a pilot-tested semi-structured interview that used a combination of openended and structured questions with probes (Appendix A) to assess: reasons for attending the clinic, understandings of the clinic's purpose, thoughts about the meaning of "high risk" and about breast cancer (its causes, whether it can be prevented), thoughts about personal risk, and attitudes towards prevention recommendations. Twelve interviews were conducted in person on the day of the clinic visit. Because of time constraints on busy clinic days, the remaining interviews (21/ 33) were conducted over the phone within 4 weeks of the patient's visit. All interviews were tape-recorded and transcribed verbatim.

Qualitative analysis of the interview transcripts was guided by the constant comparative-or grounded theory method described by Willms et al., ${ }^{30}$ Crabtree and Miller, ${ }^{29}$ and Strauss and Corbin. ${ }^{35}$ While informed by theory, this inductive approach avoids applying a priori hypotheses and meanings to study data, seeking instead to identify themes and definitions relevant for future hypothesis generation. The study questions and semi-structured questionnaire guided the development of broad coding categories (e.g., causal theories, risk perceptions, ideas about prevention). Using these categories, 3 investigators-a social scientist (T.S.), clinician (P.S.G.), and epidemiologist (D.S.L.)—read through and coded a subset of transcripts, which were then compared for consistency. Areas of divergence were discussed and resolved through consensus and a final coding list incorporating more specific sublevels of coding was approved.

Using NVIVO (QSR International ${ }^{\odot}$ ) software, 1 investigator (T.S.) coded the remaining transcripts, meeting regularly with coinvestigators to discuss nascent conceptual models (e.g., the meaning of "risk" or how to prevent breast cancer) emerging from repetitions, relative frequencies, and cooccurrences of agreed-upon codes. Consistent with grounded theory, emerging concepts were integrated into ongoing interview questions to assess their validity. After initial data analysis, follow-up interviews of eleven return patients further explored and validated key findings. Theory triangulation situated the findings within the existing literature.

\section{RESULTS}

The following analysis uses a combination of tabular and textual data to present risk perceptions and prevention attitudes among the study population. Numerical data in tables on risk perceptions and prevention attitudes are presented to demonstrate the strength of responses to coded themes. This data format reflects the nature of semi-structured interviews, where respondents frequently provided multiple responses within question domains, resulting in totals exceeding the number of respondents. The qualitative text is treated as a unique and essential source of data (see Appendix B for additional text excerpts).

\section{Characteristics of the Sample}

Table 1 shows demographic and health characteristics of the 33 participants. Most were African American, unmarried, and 
Table 1. Characteristics of Interview Sample $(n=33)$

\begin{tabular}{|c|c|}
\hline Demographics & $n(\%)$ \\
\hline \multicolumn{2}{|l|}{ Ethnicity $(n=33)$} \\
\hline African American & $24(73)$ \\
\hline White & $6(18)$ \\
\hline Other (Hispanic, Asian) & $3(9)$ \\
\hline \multicolumn{2}{|l|}{ Age $(n=33)$} \\
\hline Average age [range] & 55 [33 to 77$]$ \\
\hline 30 to 39 & $4(12)$ \\
\hline 40 to 49 & $5(15)$ \\
\hline 50 to 59 & $12(36)$ \\
\hline$\geq 60$ & $12(36)$ \\
\hline \multicolumn{2}{|l|}{ Education (y, $n=30$ ) } \\
\hline$<12$ & $9(30)$ \\
\hline 12 & $9(30)$ \\
\hline 13 to 15 & $9(30)$ \\
\hline $16+$ & $3(10)$ \\
\hline \multicolumn{2}{|l|}{ Marital status $(n=31)$} \\
\hline Divorced/widowed & $12(39)$ \\
\hline Married & $10(32)$ \\
\hline Single & $9(29)$ \\
\hline \multicolumn{2}{|l|}{ Employment status $(n=32)$} \\
\hline Employed & $13(41)$ \\
\hline Retired & $8(25)$ \\
\hline Not employed & $7(22)$ \\
\hline Disability & $4(12)$ \\
\hline \multicolumn{2}{|l|}{ Religious affiliation $(n=24)$} \\
\hline Baptist & $13(54)$ \\
\hline Catholic & $5(21)$ \\
\hline Nondenomination/other protestant & $4(17)$ \\
\hline Jewish & $1(4)$ \\
\hline Muslim & $1(4)$ \\
\hline \multicolumn{2}{|l|}{ Health variables } \\
\hline \multicolumn{2}{|l|}{ High-risk clinic $(n=33)$} \\
\hline Return patients & $25(76)$ \\
\hline New patients & $8(24)$ \\
\hline \multicolumn{2}{|l|}{ Referral source $(n=33)$} \\
\hline Physician referral & $32(97)$ \\
\hline Self-referred & $1(3)$ \\
\hline \multicolumn{2}{|l|}{ Breast cancer risk ${ }^{*}$} \\
\hline \multicolumn{2}{|l|}{ Gail $5 y^{\dagger}(n=32)$} \\
\hline Average (range) & $2.7(0.8$ to 7.0$)$ \\
\hline$\geq 1.67 \%$ & $18(56)$ \\
\hline$<1.67 \%$ & $14(44)$ \\
\hline \multicolumn{2}{|l|}{ BRCA carrier $^{\ddagger}(n=32)$} \\
\hline High risk & $11(34)$ \\
\hline Moderate/high risk & $8(25)$ \\
\hline Moderate risk & $6(19)$ \\
\hline Low/moderate risk & $5(12)$ \\
\hline Low risk & $2(6)$ \\
\hline "Moderate to high risk"§ & $29(88)$ \\
\hline \multicolumn{2}{|l|}{ Comorbidities $^{\|} \quad(n=33)$} \\
\hline 0 & $6(18)$ \\
\hline 1 & $10(30)$ \\
\hline 2 & $8(24)$ \\
\hline$>2$ & $9(27)$ \\
\hline
\end{tabular}

*As documented in the patient's medical record.

A Gail 5-year risk value of $1.67 \%$ or above is considered appropriate for prescribing tamoxifen for risk reduction. ${ }^{37}$

${ }^{\ddagger} B R C A$ carrier risk is a physician’s assessment of hereditary cancer risk based on consideration of the patient's family cancer history.

${ }^{\S}$ Refers to patients who had an elevated Gail risk or were categorized as having moderate, moderate/high, or high BRCA carrier risk.

"Self-reported health conditions currently under treatment or assessment by a physician. Includes: diabetes, hypertension, lupus, arthritis, heart problems, emphysema/asthma/COPD, depression, and menopausal symptoms.

not employed and had no greater than a high school education. A majority of those mentioning a religious affiliation were Baptist. Most had previously attended the clinic and were physi-
Table 2. Interview Responses: Risk*

\begin{tabular}{|c|c|}
\hline & $\begin{array}{l}\text { Persons responding } \\
(\%)^{\dagger}\end{array}$ \\
\hline \multicolumn{2}{|l|}{ 1. Personal risk perceptions } \\
\hline \multicolumn{2}{|l|}{$\begin{array}{l}\text { a. "Where does breast cancer fit into your other } \\
\text { health problems?" }(n=33)\end{array}$} \\
\hline Bottom of list & $12(36)$ \\
\hline Don't think about it & $6(18)$ \\
\hline On top of list & $4(12)$ \\
\hline All mixed up together & 3 (9) \\
\hline No response/not applicable ${ }^{\ddagger}$ & $8(24)$ \\
\hline \multicolumn{2}{|l|}{$\begin{array}{l}\text { b. "Do you feel like you are high risk for breast } \\
\text { cancer?" }(n=31)\end{array}$} \\
\hline Don't feel high risk & $20(65)$ \\
\hline Not sure/sometimes feel high risk & $12(39)$ \\
\hline Yes-feel high risk & $11(35)$ \\
\hline Don't think about/dwell on it & $10(30)$ \\
\hline $\begin{array}{l}\text { Women giving more than } 1 \text { response during } \\
\text { interview }^{\S}\end{array}$ & $13(42)$ \\
\hline \\
\hline \multicolumn{2}{|l|}{ (Some individuals gave multiple responses) ${ }^{\S}$} \\
\hline \multicolumn{2}{|c|}{ a. "Why did you first come to this high risk clinic?" $(n=33)$} \\
\hline For family history of cancer & $25(76)$ \\
\hline For breast problem/pain & $16(48)$ \\
\hline Seeking gene testing & $1(3)$ \\
\hline \multicolumn{2}{|l|}{$\begin{array}{l}\text { b. "What does being "high risk" mean to } \\
\text { you?" }(n=33)\end{array}$} \\
\hline Family history & $23(67)$ \\
\hline Keep an eye on it/catch it early & $15(45)$ \\
\hline Increased probability of cancer & 3 (9) \\
\hline \multirow{2}{*}{\multicolumn{2}{|c|}{$\begin{array}{l}\text { 3. Causes of breast cancer: } \\
\text { (Some individuals gave multiple responses) }^{\S} \\
\text { a. "Why do you think women get breast } \\
\text { cancer?" }(n=33)\end{array}$}} \\
\hline & \\
\hline Heredity/gene & $29(88)$ \\
\hline Emotional & $21(64)$ \\
\hline Stress/anger & 13 (39) \\
\hline Worry/dwell on it & $12(36)$ \\
\hline Don't know & $18(55)$ \\
\hline $\begin{array}{l}\text { Spiritual (God's will/"what happens } \\
\text { happens") }\end{array}$ & $14(42)$ \\
\hline Lifestyle habits & $14(42)$ \\
\hline Diet/chemicals in food & $11(33)$ \\
\hline Smoking/drinking & 5 (15) \\
\hline Not taking care of body/not getting & $7(21)$ \\
\hline \multicolumn{2}{|l|}{ checked } \\
\hline Hormones (HRT, OCT) & $8(24)$ \\
\hline Bruises/trauma to breasts & $4(12)$ \\
\hline $\begin{array}{l}\text { Reproductive risks (e.g., age at childbirth, } \\
\text { breastfeeding) }\end{array}$ & $3(9)$ \\
\hline Large breasts & $2(6)$ \\
\hline
\end{tabular}

*Question format varied. See Appendix A.

${ }^{\dagger}$ Some individuals did not respond to all questions.

${ }^{\ddagger}$ Several individuals had no co-morbidities (see Table 1).

${ }^{\S}$ Because some individuals gave multiple responses per category, percent totals do not add up to 100\%. Quantities indicate the strength of response to themes identified in the qualitative coding.

cian-referred. Nearly $90 \%$ of participants were high risk with a Gail risk greater than $1.67 \%$ and/or a moderate to high risk for carrying a BRCA mutation. None had a personal history of breast cancer. Over $80 \%$ reported at least 1 significant comorbid illness.

\section{Breast Cancer Risk Perceptions}

Table 2 presents types of response to questions assessing breast cancer concerns, self-perceived risk, meaning of "high risk," and ideas about the causes of breast cancer. 
Personal Risk Perceptions. Breast cancer was rarely at the top of the list of individual health concerns and interviewees predominantly reported that they did not feel high risk or were not sure. Over one-third of women gave more than 1 response while others claimed they "sometimes" felt high risk. These patterns of response suggest that many women considered their risk status to be something that fluctuates. Analysis of the qualitative text suggests that this contingency relates to an understanding of risk as stemming from physical problems and not as a fixed statistical probability.

[I don't feel high risk because] I never had nothing hurting ... no lumps or nothing in my breast. (JS13)

... Maybe [I would feel high risk] if I find a lump or something. Or even if I have some different feelings about myself, my body ... I don't feel like I'm a high risk patient or anything like that. It's like I say, I really like coming to the clinic, ah, just in case there's something going on, you know, so the doctor can maybe, ah, catch it in time ... (JS33)

The pattern of personal risk perception responses and qualitative textual responses jointly reveal an underlying sense that one becomes "high risk" as a result of physical signs or symptoms indicating a problem or crisis. Rather than being understood as a chronic presymptomatic illness state, as has been proposed in the literature, ${ }^{36}$ personal risk as defined here is contingent, embodied, and dependent on the findings from a mammogram or doctor's exam.

Responding to direct questions about perceived breast cancer risk, some women explained that they preferred not to, "think about it," "claim it," or "dwell on it." The qualitative text reveals a concern that if one "dwells" on cancer or "claims" it (i.e., names it or worries about it), it might cause cancer or bring it on sooner.

Because when you dwell on things like that, sometimes it happens. . . (JS2)

When my mammogram comes back and it be alright, I feel okay, I try not to think about it because they say don't dwell on it, so I try not to dwell on it. . . Because a lot of the time they say if you got something and you just think, think, think, think, that it makes it worser . . (JS15)

I don't even concentrate on that kind of stuff. ... You can worry yourself into things. I'm not that type of person. . I got enough that's come up on me, I'm not going to worry myself up on nothing. (JS4)

This reluctance to think about breast cancer risk also suggests a unique causal model.

Meaning of "High Risk." Women appeared to recognize the clinical significance of a family history of cancer in their responses to questions about reasons for attending a high risk clinic and about the meaning of "high risk." However, other response categories show that breast problems and the need for careful watching continued to underlay the significance of "high risk" for many women. In discussing their "objective" risk status, respondents frequently used qualifications such as, "they say" "they assume" or "that's what they told me."

So, for them, they assume that I could be at high risk for cancer. . . (JS23)

The narrative structures of many women's responses revealed a conflict between a concept of risk as a personally experienced state of physical change and as an objective, medical designation.

High risk . . means that, I thought maybe I had some signs of cancer and they wanted to keep an eye on it or something. But then when I take the mammogram, they all come out alright. And then I asked her why did they send me, and she said, because they consider you high risk because it's in your family. (JS12) Well, at first, they wanted to know my family history. So, for them, they assume that I could be at high risk for cancer. So, they brought me here ... because of the family history. . . [But] what they found in my breast, is that it wasn't no cancer. It was like, hard tissue. (JS23)

In short, while recognizing the objective criteria used to assign them to a high risk clinic, many women continued to express a more personal understanding of risk that relied on physical experiences and characteristics. Consistent with this interpretation, only 3 respondents defined "high risk" probabilistically, suggesting the low value placed on medical or numerical models of risk.

Causes of Breast Cancer. Respondents again demonstrated awareness of their hereditary risk in discussing breast cancer causality. However, echoing the reluctance to "dwell on" breast cancer risk observed above, women frequently asserted that cancer can be brought on by stress, anger, worry, or "dwelling on it." While some relied on spiritual statements of acceptance ("what happens, happens"), more could not provide causal explanations for breast cancer ("don't know"), perhaps reflecting a reluctance to "claim" or dwell on this topic. Some mentioned personal lifestyle features (diet, keeping appointments) that might explain breast cancer, although faith in keeping one's doctors' appointments could reflect a selection bias of the women participating in this study. Furthermore, examining specific dietary risks shows that they included both "internal" risks such as dietary habits as well as "external" risks such as chemicals in one's food, suggesting underlying complexity to stated lifestyle risks.

[Cancer] comes from the food. ... the pesticide that they put on the vegetables when you wash it, you might not wash it all off. And, the different things that they put on the meat to preserve it. (S28)

Exogenous hormones (HRT, oral contraceptives) and physical characteristics (large breasts, physical trauma) were less common categories of response. Few women cited reproductive risks (e.g., nulliparity, early menarche) as causes of breast cancer, even though these form the basis for Gail risk calculations.

\section{Breast Cancer Prevention}

Table 3 presents responses to questions about interest in available prevention options, ideas about preventing breast cancer, and desire for gene testing.

Prevention Choices and Attitudes. Most women queried were not interested in or were unsure about taking a medication to prevent cancer, regardless of whether they had been offered it. These included women who disliked taking pills or feared the harmful effects of such medications.

I'm not going to create no monsters. [Medications] just mess you up! (JS4)

That is, the competing "risks" of more pressing health conditions informed their breast cancer risk self-perceptions and their willingness to engage in therapeutic prevention. Others indicated a more complex understanding of the relationship between preventive medications and cancer.

You know, but then again sometimes the preventive thing that you take irritates the cell that you've got to wake it up. (JS9) 
Table 3. Interview Responses: Prevention*

\begin{tabular}{|c|c|}
\hline & Persons responding (\%) \\
\hline \multicolumn{2}{|l|}{ 1. Preventive choices and attitudes } \\
\hline \multicolumn{2}{|l|}{$\begin{array}{l}\text { a. "Would you ever take a medication to } \\
\text { prevent getting breast cancer?" }\end{array}$} \\
\hline \multicolumn{2}{|l|}{ Among all respondents $(n=32)$} \\
\hline No & $17(53)$ \\
\hline Yes & $5(15)$ \\
\hline Not sure & $6(18)$ \\
\hline Taking/taken & $3(9)$ \\
\hline \multicolumn{2}{|l|}{ Among women offered tamoxifen $(n=19)$} \\
\hline No & $13(68)$ \\
\hline Yes & $4(21)$ \\
\hline Not sure & $2(11)$ \\
\hline \multicolumn{2}{|l|}{$\begin{array}{l}\text { Reasons given for not taking tamoxifen: } \\
\text { (Some individuals gave multiple responses) }^{\ddagger}\end{array}$} \\
\hline Creates problems/cancer/side-effects & $16(50)$ \\
\hline To treat/control a problem only & $12(38)$ \\
\hline No guarantee/doesn't work & $7(22)$ \\
\hline Not a pill taker & 5 (16) \\
\hline \multicolumn{2}{|l|}{$\begin{array}{l}\text { b. "How could you prevent getting breast } \\
\text { cancer?" (Some individuals gave multiple } \\
\text { responses) })^{\ddagger}(n=33)\end{array}$} \\
\hline Early detection/keep appointments & $22(67)$ \\
\hline Lifestyle/care of body & $20(61)$ \\
\hline Can't prevent & $13(39)$ \\
\hline Faith in God/prayer & $13(39)$ \\
\hline Medications/surgery & $6(18)$ \\
\hline \multicolumn{2}{|l|}{ 2. Gene testing } \\
\hline \multicolumn{2}{|c|}{$\begin{array}{l}\text { a. "Would you ever take a gene test to } \\
\text { find out if breast cancer runs in your family?" }\end{array}$} \\
\hline \multicolumn{2}{|l|}{ All respondents $(n=29)$} \\
\hline Yes & $16(55)$ \\
\hline Not sure/unclear & $7(24)$ \\
\hline No & $6(21)$ \\
\hline Had testing & $0(0)$ \\
\hline \multicolumn{2}{|l|}{ Women who had genetic counseling ${ }^{\S}(n=18)$} \\
\hline Yes & $11(61)$ \\
\hline Not sure/unclear & $3(17)$ \\
\hline No & $4(22)$ \\
\hline Had testing & $0(0)$ \\
\hline
\end{tabular}

* Question format varied. See Appendix A.

'Some individuals did not respond to all questions.

${ }^{\ddagger}$ Because some individuals gave multiple responses per category, percent totals do not add up to 100\%. Quantities indicate the strength of response to themes identified in the qualitative coding.

${ }^{\S}$ Includes previous genetic risk counseling by a physician or genetic counselor.

Some noted that such medications are suspect particularly when there is no guarantee that they will prevent cancer. Despite tamoxifen's demonstrated $50 \%$ breast cancer risk reduction, ${ }^{37}$ the expressed need for a guaranteed outcome indicates a reluctance to accept the statistical arguments of evidencebased medicine.

Significantly, many women noted that a medication is taken only when a problem arises, to control it. This explanation corresponds to the understanding of risk expressed abovenamely that it is a response to a crisis or immediate physical problem.

I feel, why take it if you don't have anything? (JS22)

You can control it, but you can't prevent it ... I take [blood pressure medication] because I know my husband had high blood pressure and I know it can be dangerous. . But all these other medicines to prevent you from getting it, you can't. . It slows it down, but you don't stop it, because I feel if it's for you, you're going to get it. If it's going to be, it's going to be. (JS12)
In addition to demonstrating contradictory attitudes toward taking hypertension medications and breast cancer chemoprevention, the above response exemplifies a common reply to questions about prevention in Table 3 (i.e., breast cancer cannot be prevented, "what happens, happens"). Skepticism of primary prevention is apparent in the frequent emphasis on early detection as the best "prevention" strategy (vs medications or surgery) and an expressed reliance on prayer and spiritual healing to cope with the threat of cancer. While a selection bias may again explain the faith in regular screening in this clinic population, the latter finding echoes causal statements in Table 2 indicating a spiritual acceptance of eventualities perceived to be outside of individual control. Conversely, many women also insisted on the causal and prevention value of lifestyle behaviors and self-empowered action ("take care of self/keep appointments"). Whether this apparent contradiction is a function of overlapping health concerns, internalizing doctors' recommendations, and/or distinct religious or cultural beliefs warrants exploration.

Gene Testing. In contrast to chemoprevention, interest in testing for gene mutations in BRCA1 or BRCA2 was relatively high among those who had and had not been provided information about it, even though only 1 woman initially visited the clinic seeking gene testing (Table 2). Yet, only 2 women expressed considering prophylactic surgery and 2 others mentioned considering chemoprevention in response to gene testing results. Some of those not interested in testing cited concern that information about a gene might cause excessive worry. However, economic constraints hindered identifying patient barriers to testing. Despite the best efforts of the physician and genetic counseling staff, limited financial assistance meant that eligible but uninsured patients rarely received the $\$ 3,000$ test. Overall, the absence of testing precluded more thorough exploration of decision making around gene mutation carrier status.

\section{CONCLUSION}

This study presents unique data on the meanings underlying the experiences and choices of women attending a public hospital high risk breast cancer clinic. It identifies important differences between the risk perceptions and prevention attitudes expressed by study participants and medical approaches to breast cancer risk and prevention. In general, the women in this study appeared to understand risk not as a numerical probability or chronic disease state suitable for prophylaxis but as an immediate physical sign or symptom warranting medical intervention or early detection. Despite understanding their categorization as "high risk," many women did not feel high risk and thus were unwilling to take a medication that may itself cause problems. Furthermore, reluctance to state one's personal risk and concern about the health effects of worrying signify an etiological model different from the causal (i.e., hormonal) logic underlying current prevention strategies. Such tendencies may also directly oppose physicians' efforts to maintain their patients' risk awareness. Lastly, the assumption that knowing risk will help control one's future health ${ }^{38,39}$ may conflict with the spiritual faith, skepticism about the preventability of cancer, and failure to ascribe breast cancer causality among some women in this study. 
Prior qualitative research on cultural attitudes to breast cancer within African American populations supports the validity of our results. Other studies have similarly noted a reluctance to "claim" a cause by naming it ${ }^{40,41}$; medical care sought for a problem, not prevention ${ }^{42}$; causal attributions to worry and stress ${ }^{32,41,43}$; mistrust of harmful treatments ${ }^{32,41,43}$; and belief in an early disease state when cancer can be caught. ${ }^{32,41}$ Acceptance of uncertainty and resignation to fate in the context of illness has also been noted elsewhere among lay populations. ${ }^{44}$ However, further research should explore the extent to which this study's findings stem from cultural, ethnic, socioeconomic factors, or a combination.

Unlike chemoprevention, genetic testing was not strongly resisted by study participants. This may be related to the relatively unthreatening nature of genetic information (vs a medication) and/or incomplete understanding of its consequences. Such interest remains hypothetical, however; structural limitations precluded identifying uptake of gene testing or subsequent prevention behaviors in this uninsured population. More funding and research is needed in order to examine how similar populations understand gene testing and the risk information it provides and to assess the acceptability of prophylactic options such as mastectomy or oophorectomy.

The main limitation of this study is the use of a convenience sample of high risk English-speaking women. Our results may not generalize to high risk clinics where most patients are insured or self-referred or to ethnic or minority groups that include non-English speakers. Also, those seeking regular screening were more likely enrolled in the study, so results may not apply to those who do not seek regular screening. Finally, data gathered by in-person versus telephone interview modes may not be the same. However, other qualitative researchers have found comparable data quality with combined modes. ${ }^{45-47}$ No differences were observed in the number of respondents citing the prevention value of keeping their appointments (data not shown) between those interviewed by phone versus in-person suggesting desirability bias did not affect responses to in-person interviews. Furthermore, interview questions assessed attitudes unlikely to be affected by recall bias over the telephone.

This study has implications for primary care prevention activities and related research. Improving risk communication and prevention counseling to minimize health disparities might include reframing chemoprevention discussions in terms of controlling "early" undetectable cancers. ${ }^{48}$ Clarifying the conceptual relationship between spirituality and lifestyle risks could lead to strategies for educating and empowering patients. The relevance of comorbidities for risk perceptions and prevention decision-making within this high risk population suggests that similar individuals in greater contact with the medical system because of multiple competing health risks might also be less willing to undertake medical prevention recommendations for an asymptomatic risk state.

Additionally, the frequent denial of feeling "high risk" and reluctance to "think about it" suggest cautious interpretation of survey or instrument-based assessments of personal risk perceptions. This may be particularly salient for quantitative measures of risk perception where a nonresponse, denial, or underestimation of risk may be a proxy for a particular conceptual model of explanation not sufficiently operationalized by that instrument. ${ }^{10}$ Lastly, additional research in similar populations should further examine the relationship between risk perceptions and prevention decisions. Although this research provides a glimpse into sophisticated health behavioral models, more in-depth study is clearly needed.

This research was funded by a pre-doctoral grant from the Breast Cancer Research Program, Department of Defense Congressionally Directed Medical Research Programs (Award \#W81XWH-04-1-0333). Dr. Olopade is a Doris Duke Distinguished Clinical Scientist.

\section{REFERENCES}

1. Armstrong K. Leading the way in breast cancer screening and prevention. J Gen Intern Med. 2004; 10:390-1.

2. Sugg Skinner C, Rawl SM, Moser BK, et al. Impact of the cancer risk intake system on patient-clinician discussions of tamoxifen, genetic counseling, and colonoscopy. J Gen Intern Med. 2005;20:360-5.

3. Sakorafas GH, Krespis E, Pavlakis G. Risk estimation for breast cancer development; a clinical perspective. Surg Oncol. 2002;10:183-92.

4. King MC, Marks JH, Mandell JB. Breast and ovarian cancer risks due to inherited mutations in BRCA1 and BRCA2. Science. 2003;302:643-6.

5. Robson ME. Clinical considerations in the management of individuals at risk for hereditary breast and ovarian cancer. Cancer Control. 2002;9:457-65.

6. U.S. Preventive Services Task Force. Chemoprevention of breast cancer: recommendations and rationale. Ann Intern Med. 2002;137:56-58.

7. Schrag D, Kuntz KM, Garber JE, Weeks JC. Life expectancy gains from cancer prevention strategies for women with breast cancer and BRCAl or BRCA2 mutations. JAMA. 2000;283:617-24.

8. Grann VR, Jacobson JS, Thomason D, Hershman D, Heitjan DF, Neugut AI. Effect of prevention strategies on survival and qualityadjusted survival of women with BRCAl/2 mutations: an updated decision analysis. J Clin Oncol. 2002;20:2520-9.

9. Haas JS, Kaplan CP, Gregorich SE, Pérez-Stable EJ, des Jarlais G. Do physicians tailor their recommendations for breast cancer risk reduction based on patient's risk? J Gen Intern Med. 2004;19:302-9.

10. Hopwood P. Breast cancer risk perception: what do we know and understand? Breast Cancer Res. 2000;2:387-91.

11. Lerman C, Hughes C, Croyle RT, et al. Prophylactic surgery decisions and surveillance practices one year following BRCAl/2 testing. Prev Med. 2000;31:75-80.

12. Hughes C, Lerman C, Lustbader E. Ethnic differences in risk perception among women at increased risk for breast cancer. Breast Cancer Res Treat. 1996;40:25-35.

13. Donovan KA, Tucker DC. Knowledge about genetic risk for breast cancer and perceptions of genetic testing in a sociodemographically diverse sample. J Behav Med. 2000;23:15-36.

14. Eisinger F, Julian-Reynier C, Sobol H, Stoppa-Lyonnet D, Lasset C, Nogues C. Acceptability of prophylactic mastectomy in cancer-prone women. JAMA. 2000;283:202-3.

15. Ang P, Yong K-Y, Tan K-S. Low acceptance of prophylactic surgery and chemoprevention even in individuals at increased risk of cancer in Singapore. ASCO Annual Meeting 2003. Proc Am Soc Clin Oncol. 2003;22:540 (abstr 2174).

16. Meiser B, Eisenbruch M, Barlow-Stewart K, Tucker K, Steel Z, Goldstein D. Cultural aspects of cancer genetics: setting a research agenda. J Med Genet. 2001;38:425-9.

17. Sanders T, Campbell R, Sharp D, Donovan J. Risk constructions among people who have a first-degree relative with cancer. Health Risk Soc. 2003;5:53-69.

18. Bouchard L, Blancquaert I, Eisinger F, et al. Prevention and genetic testing for breast cancer: variations in medical decisions. Soc Sci Med. 2004;58:1085-96.

19. Julian-Reynier C, Eisinger F, Evans G, Foulkes W, Sobol H. Variation in prophylactic surgery decisions. Lancet. 2000;356:1687.

20. Hughes C, Fasaye GA, LaSalle VH, Finch C. Sociocultural influences on participation in genetic risk assessment and testing among African American women. Patient Educ Couns. 2003;51:107-14.

21. Hallowell N, Jacobs I, Richards M, Mackay J, Gore M. Surveillance or surgery? A description of the factors that influence high risk premenopausal women's decisions about prophylactic oophorectomy. J Med Genet. 2001;38:683-91. 
22. Eisinger F, Geller G, Burke W, Holtzman NA. Cultural basis for differences between US and French clinical recommendations for women at increased risk of breast and ovarian cancer. Lancet. 1999;353:919-20.

23. Chalmers $\mathbf{K}$, Thomson $\mathbf{K}$. Coming to terms with the risk of breast cancer: perceptions of women with primary relatives with breast cancer. Qual Health Res. 1996;6:256-82.

24. Lannin DR, Mathews HF, Mitchell J, Swanson MS. Impacting cultural attitudes in African-American women to decrease breast cancer mortality. Am J Surg. 2002;184:418-23.

25. Kerner JF. Breast cancer prevention and control among the medically underserved. Breast Cancer Res Treat. 1996;40:1-9.

26. Guidry JJ, Matthews-Juarez P, Copeland VA. Barriers to breast cancer control for African-American women: the interdependence of culture and psychosocial issues. Cancer. 2003;97:318-23.

27. Marcus AC. New directions for risk communication research: a discussion with additional suggestions. $J$ Natl Cancer Inst Monogr. 1999;25:35-42.

28. Stefanek M, Hartmann L, Nelson W. Risk-reduction mastectomy: clinical issues and research needs. J Natl Cancer Inst. 2001;93:1297-306.

29. Crabtree BF, Miller WL. Doing Qualitative Research in Primary Care: Multiple Strategies. Thousand Oaks, CA: Sage Publications; 1992.

30. Willms DG, Best JA, Taylor DW, et al. A systematic-approach for using qualitative methods in primary prevention research. Med Anthropol Quart. 1990;4:391-409.

31. Rajaram SS, Rashidi A. Minority women and breast cancer screening: the role of cultural explanatory models. Prev Med. 1998;27:757-64.

32. Gregg J, Curry RH. Explanatory models for cancer among AfricanAmerican women at two Atlanta neighborhood health centers: the implications for a cancer screening program. Soc Sci Med. 1994;39:519-26.

33. Dein S. Explanatory models of and attitudes towards cancer in different cultures. Lancet Oncol. 2004;5:119-24.

34. Davison C, Smith GD, Frank1 S. Lay epidemiology and the prevention paradox-the implications of coronary candidacy for health-education. Sociology Health Illness. 1991;13:1-19.

35. Strauss A, Corbin $\mathbf{J}$ Grounded theory methodology-an overview. In Denzin NK, Lincoln YS, eds. Handbook of Qualitative Research. Thousand Oaks, CA: Sage Publications; 1994:273-85.

\section{Supplementary Material}

The following supplementary material is available for this article online at www.blackwell-synergy.com Appendix A. Interview Guide for the Semi-Structured Interview.

Appendix B. Examples of Qualitative Responses to Interview Questions.
36. Kenen R, Arden-Jones A, Eeles RA. Living with chronic risk: healthy women with a family history of breast/ovarian cancer. Health Risk Soc. 2003;5:315-31.

37. Martino S, Costantino J, McNabb M, et al. The role of selective estrogen receptor modulators in the prevention of breast cancer: comparison of the clinical trials. Oncologist. 2004;9:116-25.

38. Skolbekken JA. The risk epidemic in medical journals. Soc Sci Med. 1995;40:291-305.

39. Jacobs LA. An analysis of the concept of risk. Cancer Nurs. 2000;23: 12-9.

40. Mathews HF, Lannin DR, Mitchell JP. Coming to terms with advanced breast cancer: black women's narratives from eastern North Carolina. Soc Sci Med. 1994;38:789-800.

41. Hoffman-Goetz L, Mills SL. Cultural barriers to cancer screening among African American women: a critical review of the qualitative literature. Womens Health. 1997;3:183-201.

42. Tessaro I, Eng E, Smith J. Breast cancer screening in older AfricanAmerican women: qualitative research findings. Am $\mathrm{J}$ Health Promot. 1994;8:286-92.

43. Matthews AK, Cummings S, Thompson S, List M, Olopade OI. Genetic testing of African Americans for susceptibility to inherited cancers: use of focus groups to determine factors contributing to participation. J Psych Oncol. 2000;18:1-19.

44. Davison C, Frankel S, Smith GD. The limits of lifestyle: re-assessing "fatalism" in the popular culture of illness prevention. Soc Sci Med. 1992;34:675-85.

45. Sturges JE, Hanrahan KJ. Comparing telephone and face-to-face qualitative interviewing: a research note. Qualitative Research. 2004;4: 107-18.

46. Burt J, Caelli K, Moore K, Anderson M. Radical prostatectomy: men's experiences and postoperative needs. J Clin Nurs. 2005; 14:883-90.

47. Tomaino-Brunner C, Freda MC, Runowicz CD. "I hope I don't have cancer": colposcopy and minority women. Oncol Nurs Forum. 1996;23:39-44

48. Baty BJ, Kinney AY, Ellis SM. Developing culturally sensitive cancer genetics communication aids for African Americans. Am J Med Genet. 2003; 118A: 146-55. 